\title{
The Chemiluminescence and Structure Properties of Normal/Inverse Diffusion Flames
}

\author{
Ting Zhang, Qinghua Guo, Xudong Song, Zhijie Zhou, and Guangsuo Yu
}

Key Laboratory of Coal Gasification and Energy Chemical Engineering of Ministry of Education, East China University of Science and Technology, Shanghai 200237, China

Correspondence should be addressed to Guangsuo Yu; gsyu@ecust.edu.cn

Received 28 June 2012; Accepted 25 September 2012

Academic Editor: Masaki Oura

Copyright (c) 2013 Ting Zhang et al. This is an open access article distributed under the Creative Commons Attribution License, which permits unrestricted use, distribution, and reproduction in any medium, provided the original work is properly cited.

\begin{abstract}
The flame emission spectrometry was applied to detect the distribution of excited radicals in two types $\mathrm{CH}_{4} / \mathrm{O}_{2}$ coflow jet diffusion flames (normal and inverse diffusion flames). Combining the image analysis along with the spectrometry, the chemiluminescence and structure characteristics of these diffusion flames were investigated. The results show that the inverse diffusion flame (IDF) with relatively high inlet oxygen velocity is composed of two regions: a bright base and a tower on top of the base, which is quite different from the normal diffusion flame (NDF). The flame is divided into two regions along the flame axis based on maximum $\mathrm{OH}^{*}$ position (Region I: initial reaction zone; Region II: further oxidation zone). The degree of the further oxidization taking place in Region II is obvious in accordance with $\mathrm{OH}^{*}$ distribution, which is the main difference in reaction zone between fuel-rich condition and fuel-lean condition for NDFs. For IDFs, the change of $\mathrm{OH}^{*}$ distribution with increasing equivalence $\mathrm{O} / \mathrm{C}$ ratio $\left([\mathrm{O} / \mathrm{C}]_{e}\right)$ in Region II is not conspicuous. More $\mathrm{OH}^{*}$ and $\mathrm{CH}^{*}$ are generated in IDFs, due to the inner high-speed $\mathrm{O}_{2}$ flow promoting the mixing of fuel and oxygen to a certain extent.
\end{abstract}

\section{Introduction}

Most of the practical combustion systems such as coal gasifiers, gas turbine engines and industrial stoves. employ diffusion combustion because of its better flame stability, safety, and wide operating range as compared to premixed combustion [1]. According to the feeding pattern of the fuel and oxidizer, there are two types of diffusion flames: normal diffusion flame (NDF) and inverse diffusion flame (IDF). The IDF is a special flame with an inner oxidizer jet surrounded by an outer fuel jet, with less soot produced as compared to NDF [2], so that the application of IDF in industry is becoming more and more widespread. In some processes of coal gasification, the combustion of inner oxygen and fuel from the annulus forms the IDF. In the coke oven gas autothermal reforming technology, the flame type is a typical IDF [3].

In recent times, there has been a growing interest in researching of IDF and its difference with NDF. The first detailed investigation was performed by $\mathrm{Wu}$ [4] for laminar methane IDF stabilized in a simple coaxial burner. $\mathrm{He}$ identified six different regimes of IDF and found that IDF and NDF had almost the same visible appearance in the confined space. The comparative study on hydrogen IDF and NDF performed by Takagi et al. [5] revealed the occurrence of higher flame tip temperature in IDF than NDF. They defined a parameter called $\mathrm{H}_{2}$ ratio to explain the occurrence of higher flame tip temperature in $\mathrm{H}_{2}$ IDF and the excess enthalpy in the central region of IDF. Kaplan and Kailasanath [6] numerically analyzed the flow field effects of air-fuel jets on soot formation in laminar methane IDF and NDF configurations and observed less peak soot volume fraction in IDF as compared to NDF. Mikofski et al. [7] measured the flame height of laminar IDFs, and predicted it using Roper's analysis for circular port burners. Based on the fact that Roper's analysis could be well applied to IDFs, they suggested that IDFs were similar in structure to NDFs. Sze et al. [8] conducted experiments on LPG-air IDFs stabilized on two different burners (one with circumferentially arranged ports and the other with coaxial jets) and reported the flame shape, visible flame length, temperature contour, and centerline oxygen concentration of these two different IDFs. 
TABLE 1: Flame conditions ${ }^{\mathrm{a}}$ used in different experiment numbers.

\begin{tabular}{|c|c|c|c|c|c|c|c|c|c|c|}
\hline \multicolumn{6}{|c|}{ NDF } & \multicolumn{5}{|c|}{ IDF } \\
\hline & $\begin{array}{c}v_{\mathrm{CH}_{4}} \\
(\mathrm{~L} / \mathrm{min})\end{array}$ & $\begin{array}{l}u_{\mathrm{CH}_{4}} \\
(\mathrm{~m} / \mathrm{s})\end{array}$ & $\begin{array}{c}v_{\mathrm{O}_{2}} \\
(\mathrm{~L} / \mathrm{min})\end{array}$ & $\begin{array}{c}u_{\mathrm{O}_{2}} \\
(\mathrm{~m} / \mathrm{s})\end{array}$ & {$[\mathrm{O} / \mathrm{C}]_{e}$} & $\begin{array}{c}v_{\mathrm{CH}_{4}} \\
(\mathrm{~L} / \mathrm{min})\end{array}$ & $\begin{array}{l}u_{\mathrm{CH}_{4}} \\
(\mathrm{~m} / \mathrm{s})\end{array}$ & $\begin{array}{c}v_{\mathrm{O}_{2}} \\
(\mathrm{~L} / \mathrm{min})\end{array}$ & $\begin{array}{c}u_{\mathrm{O}_{2}} \\
(\mathrm{~m} / \mathrm{s})\end{array}$ & {$[\mathrm{O} / \mathrm{C}]_{e}$} \\
\hline 1 & & & 0.60 & 1.52 & 0.60 & & & 0.60 & 19.90 & 0.60 \\
\hline 2 & & & 0.65 & 1.65 & 0.65 & & & 0.65 & 21.56 & 0.65 \\
\hline 3 & & & 0.70 & 1.78 & 0.70 & & & 0.70 & 23.22 & 0.70 \\
\hline 4 & & & 0.75 & 1.90 & 0.75 & & & 0.75 & 24.88 & 0.75 \\
\hline 5 & & & 0.80 & 2.03 & 0.80 & & & 0.80 & 26.54 & 0.80 \\
\hline 6 & & & 0.85 & 2.16 & 0.85 & & & 0.85 & 28.20 & 0.85 \\
\hline 7 & 0.50 & 16.59 & 0.90 & 2.29 & 0.90 & 0.50 & 1.27 & 0.90 & 29.86 & 0.90 \\
\hline 8 & & & 0.95 & 2.41 & 0.95 & & & & & \\
\hline 9 & & & 1.00 & 2.54 & 1.00 & & & & & \\
\hline 10 & & & 1.05 & 2.67 & 1.05 & & & & & \\
\hline 11 & & & 1.10 & 2.79 & 1.10 & & & & & \\
\hline 12 & & & 1.15 & 2.92 & 1.15 & & & & & \\
\hline 13 & & & 1.20 & 3.05 & 1.20 & & & & & \\
\hline
\end{tabular}

a the IDF is blown out when $u_{\mathrm{O}_{2}}$ is up to $30 \mathrm{~m} / \mathrm{s}$.

In general, previous investigations were concerned mainly with the differences of soot formation characteristics, flame temperature, and flame appearance between NDFs and IDFs. There have been very few investigations on flame chemiluminescence characteristic, which is a common approach for characterizing the flame reaction zones, flame structures, and process parameters, such as fuel type, equivalence ratio, and strain rate [9-11]. The interest of this paper is mainly focused on the chemiluminescence distribution characteristics of excited radicals $\left(\mathrm{OH}^{*}\right.$ and $\left.\mathrm{CH}^{*}\right)$ along the axis of NDFs and IDFs with different equivalence $\mathrm{O} / \mathrm{C}$ ratios. Furthermore, the detailed differences of flame reaction zones and flame structures between NDFs and IDFs are investigated by analyzing the chemiluminescence property.

\section{Experimental Setup}

2.1. Combustion System. Figure 1 shows a schematic diagram of the experimental setup, consisting of two main parts, a stainless steel combustion chamber and an optical measurement system. The height of the chamber was $200 \mathrm{~mm}$, with an i.d. of $50 \mathrm{~mm}$. A jet burner was mounted inside the chamber at the bottom. The burner consisted of two coaxial tubular layers: the inside tube had an i.d. of $0.8 \mathrm{~mm}$, and an o.d. of $1.8 \mathrm{~mm}$; the outer tube had an i.d. of $3 \mathrm{~mm}$. The flow rate was measured with mass flowmeter (Sevenstar, Inc., D07-19B). The chamber was designed to have a side quartz window to permit the optical measurement of the entire flame by a spectrometer and to record the visible flame image by a high resolution CCD camera (JAI Inc., BB-500CL).

Combustion was carried out in the chamber at atmospheric pressure. Pure methane $(>99.9 \%)$ was used as fuel, and the flow rate of fuel was kept at $0.50 \mathrm{~L} / \mathrm{min}$. Pure oxygen (>99.9\%) was used as oxidizer. The equivalence $\mathrm{O} / \mathrm{C}$ ratio

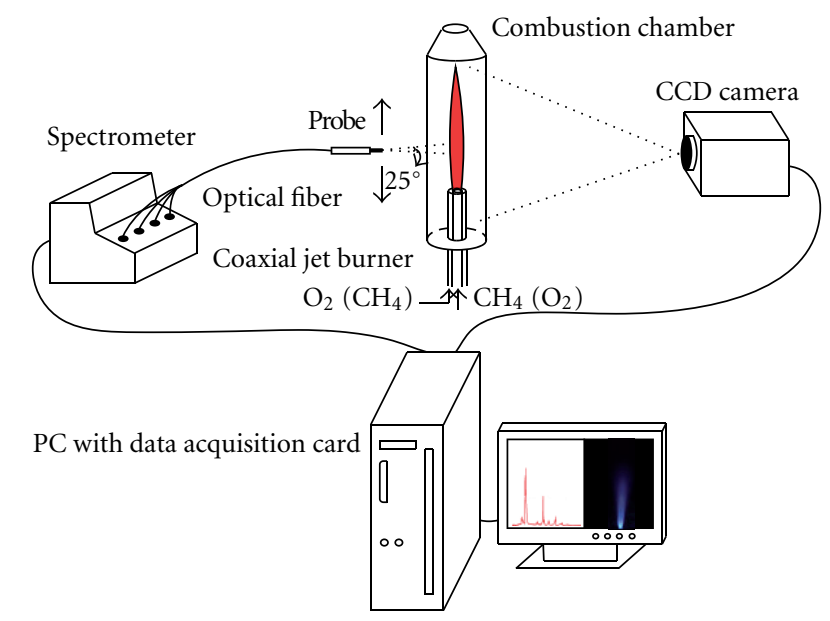

FIGURE 1: The schematic diagram of the experimental setup.

$\left([\mathrm{O} / \mathrm{C}]_{e}\right)$ was changed in a range of $0.60-1.20$, which is defined by the following equation:

$$
[\mathrm{O} / \mathrm{C}]_{e}=\frac{[\mathrm{O} / \mathrm{C}]_{a}}{[\mathrm{O} / \mathrm{C}]_{s}}
$$

where $[\mathrm{O} / \mathrm{C}]_{a}$ is the actual $\mathrm{O} / \mathrm{C}$ molar ratio calculated from the amount of fuel and oxygen feed, and $[\mathrm{O} / \mathrm{C}]_{s}$ is the stoichiometric $\mathrm{O} / \mathrm{C}$ molar ratio. The equivalence $\mathrm{O} / \mathrm{C}$ ratio was adjusted by changing $\mathrm{O}_{2}$ flow rate. Table 1 lists the numbers of experiment and conditions.

2.2. Optical Measurement Method. The optical measurement was carried out using an ocean optics spectrometer, which has the equivalent of four HR2000+ devices combined (the optical bench is a $101.6 \mathrm{~mm}$-focal length symmetrical crossed Czerny-Turner type), and each device has specific 
TABLE 2: Optical bench and settings for each HR2000+.

\begin{tabular}{|c|c|c|c|c|c|c|c|}
\hline & $\begin{array}{c}\text { Slit } \\
(\mu \mathrm{m})\end{array}$ & $\begin{array}{c}\text { Groove Density } \\
\text { (lines } / \mathrm{mm})\end{array}$ & $\begin{array}{c}\text { Grating } \\
\text { Blaze wavelength } \\
(\mathrm{nm}) \\
\end{array}$ & $\begin{array}{l}\text { Best efficiency } \\
(\mathrm{nm})\end{array}$ & $\begin{array}{l}\text { Wavelength } \\
\text { range }(\mathrm{nm})\end{array}$ & $\begin{array}{l}\text { Optical } \\
\text { resolution } \\
(\text { FWHM) }\end{array}$ & $\begin{array}{l}\text { Integration } \\
\text { time (ms) }\end{array}$ \\
\hline 1 & 5 & 1200 & 300 & $200-400$ & $200-420$ & 0.16 & 500 \\
\hline 2 & 5 & 1200 & Holographic UV & $400-800$ & $400-605$ & 0.15 & 500 \\
\hline 3 & 5 & 1200 & Holographic UV & $400-800$ & $590-780$ & 0.14 & 500 \\
\hline 4 & 5 & 1200 & 750 & $500-1100$ & $760-950$ & 0.14 & 500 \\
\hline
\end{tabular}

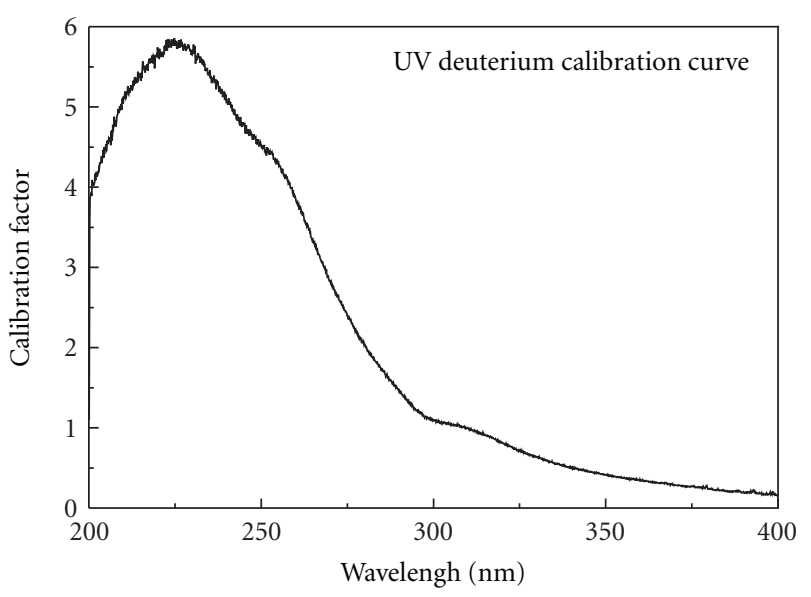

(a)

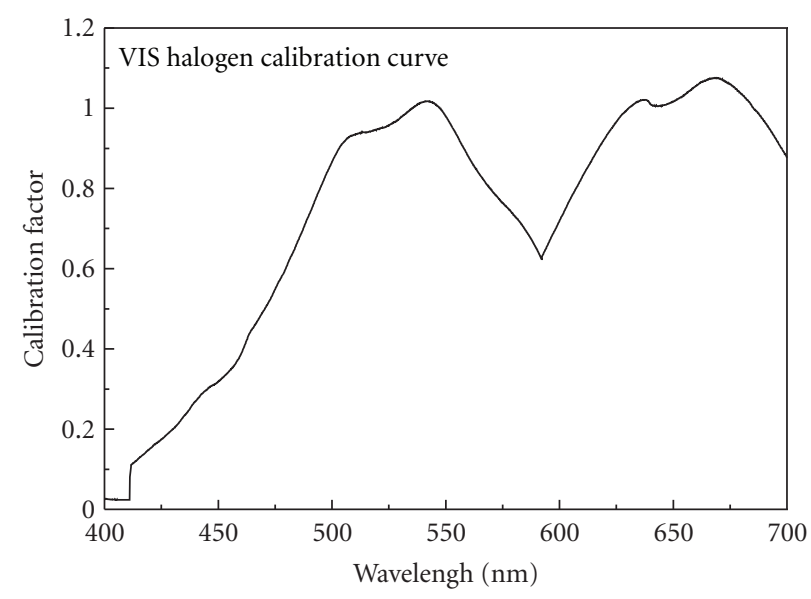

(b)

FIGURE 2: UV and VIS calibration curves.

optical bench (Table 2), detecting a certain wavelength range synchronously to achieve a high spectral resolution. A fiberoptics probe with $25^{\circ}$ field of view (FOV) and $3 \mathrm{~mm}$ diameter was directed to the flame to collect the luminescence signals. The distance from the probe to the flame was fixed in all measurements to ensure the detection of a constant projected flame area within the field of view of the fiber. The spectrum was an average of 10 spectra obtained repeatedly under the same condition. The dark background spectrum, obtained before ignition or without flame luminescence emissions for each experiment, was subtracted from the raw spectrum.

The raw intensity data collected by the spectrometer were subject to some errors: (1) losses in the intensity when the light passed through the lens; (2) attenuation losses in the optical fiber; (3) losses caused by the grating efficiency and CCD sensitivity of the spectrometer. Using a standard light source (Deuterium-Halogen lamp, Ocean Optics, Inc.) with known color temperature allowed the calibration of the optical system and reduced the errors from the lens, fiber-optic cable and the diffraction grating. The calibration factors are determined by modifying $I_{\mathrm{mi}} / I_{\mathrm{pi}}$, calculated by the following equation:

$$
\frac{I_{\mathrm{mi}}}{I_{\mathrm{pi}}}=\frac{I_{\mathrm{mi}}}{\left[C_{1} /\left(\lambda_{i}^{5} \exp \left(C_{2} / \lambda_{i} T-1\right)\right)\right]},
$$

where $I_{\mathrm{mi}}$ is the measured intensity at a given wavelength $\lambda_{i}$, $I_{\mathrm{pi}}$ is the intensity calculated by Planck's Law of Radiation at $\lambda_{i} . C_{1}=2 \pi h c^{2}, C_{2}=h c / k$, and the constants $h, k$, and $c$ are Planck's constant, Boltzmann's constant and the speed of light, respectively. Figure 2 is the calibration curve for the UV and VIS ranges. The actual intensity of the object will then be calibrated by dividing the measured intensity at $\lambda_{i}$ by the calibration factors from Figure 2. The detailed procedure refers to the publication by Keyvana et al. [12]

\section{Results and Discussion}

3.1. Typical Emissions of $\mathrm{OH}^{*}$ and $\mathrm{CH}^{*}$. In hydrocarbon flames, the major excited radical radiations come from $\mathrm{OH}^{*}$ and $\mathrm{CH}^{*}$. For $\mathrm{OH}^{*}$, the primary emission occurs at approximately $283 \mathrm{~nm}, 306 \mathrm{~nm}$, and $309 \mathrm{~nm}$. CH* radiates at about $390 \mathrm{~nm}$ and $431 \mathrm{~nm}$.

Excited radicals are formed in flames by two paths, thermal excitation and chemical excitation. Thermal excitation is related to flame temperature and the number of ground state radicals. Chemical exitation results from chemical reactions as other reactions produced ground state radicals, from which the radiation is called chemiluminescence. The thermal excitation way of $\mathrm{OH}^{*}$ becomes more dominant at temperatures above $2800 \mathrm{~K}$ [13], thus the probability of thermal excitation way effecting $\mathrm{OH}^{*}$ formation is small, which can be excluded.

Using the optical measurement system, the typical $\mathrm{OH}^{*}$ and $\mathrm{CH}^{*}$ emissions in the ultraviolet and visible regions with 
TABLE 3: Radiation data of the major excited radicals.

\begin{tabular}{|c|c|c|c|c|c|}
\hline Radical & & $\mathrm{OH}^{*}$ & & & \\
\hline Wavelength/nm & 282.9 & 306.72 & 308.9 & 388.9 & 431.42 \\
\hline Transition & & $A^{2} \Sigma^{+}-X^{2} \Pi$ & & $B^{2} \Sigma_{g}-X^{2} \Pi$ & $A^{2} \Delta-X^{2} \Pi$ \\
\hline Vibrational level & $(0,1)$ & $(0,0)$ & $(0,0)$ & $(0,0)$ & $(0,0)$ \\
\hline Comment & Q2-Line & R2-Line & Q2-Line & Q-Head & Q-Head \\
\hline
\end{tabular}

different transitions were obtained (the spectrum ranges from 200-600 nm), as shown in Figure 3. The precise radiation data are shown in Table 3.

3.2. The Comparison of Appearance between NDFs and IDFs. Figure 4 shows the visible flame images recorded by a high resolution CCD camera, and the exposure time is $1 / 100 \mathrm{~s}$. The IDF is composed of two regions: a relatively bright base and a tower on top of the base, which is different from the NDF. According to the study of Sze et al. [8], at low oxygen jet velocity, the flame shape is similar to that of a normal diffusion flame, and at high enough oxygen jet velocity $(\mathrm{Re}>$ 2500), the IDF consists of two parts: a base and a tower. In this experiment, the inlet oxygen velocity $(\operatorname{Re}>2500)$ is higher than the fuel velocity, at least 16 times higher. Wu [4] proposed that the shape of IDF is affected by both the inlet air momentum and the inlet fuel momentum. With the increase of oxygen jet velocity, the difference in the momentums of the two jets increases, leading to entrainment of some fuel into the central oxygen flow, which creates two-zone structure. When the oxygen velocity of IDF is up to $30 \mathrm{~m} / \mathrm{s}$, the flame is blown out due to the excessive jet velocity.

The flame height of IDF is smaller than NDF, indicating the flame propagation speed is relatively faster. The carbon particles produced in IDF is close to the fuel side, where the temperature is relatively low, so that the luminescence of unburned carbon particles is weaker than NDF.

3.3. The Change of $\mathrm{OH}^{*}$ Distribution with Increasing $[\mathrm{O} / \mathrm{C}]_{e}$ in NDFs. $\mathrm{OH}^{*}$ distribution can be an indication of flame reaction zone [14], and where the maximum $\mathrm{OH}^{*}$ emission is where the reaction is the most vigorous (flame-front). From the nozzle exit to the $\mathrm{OH}^{*}$ peak position, fuel and oxygen are mixed depending on the action of interdiffusion and reach the stoichiometric proportion at the $\mathrm{OH}^{*}$ peak position, where is Region I called initial reaction zone (Figure 5). In an ideal situation, the unburned fuel will be burned out when they reach the flame-front, so it can be considered that the width of the flame-front is infinitely thin. For practical flame, there are always few unburned fuel passing the flamefront (the $\mathrm{OH}^{*}$ peak position), and going on burning in the flame downstream region, where is the further oxidation zone (Region II). According the $\mathrm{OH}^{*}$ peak position, the entire flame has two regions along the axis: nozzle exit to the $\mathrm{OH}^{*}$ peak position (Region I, initial reaction zone), $\mathrm{OH}^{*}$ peak to the end of the flame propagation (Region II, further oxidation zone).

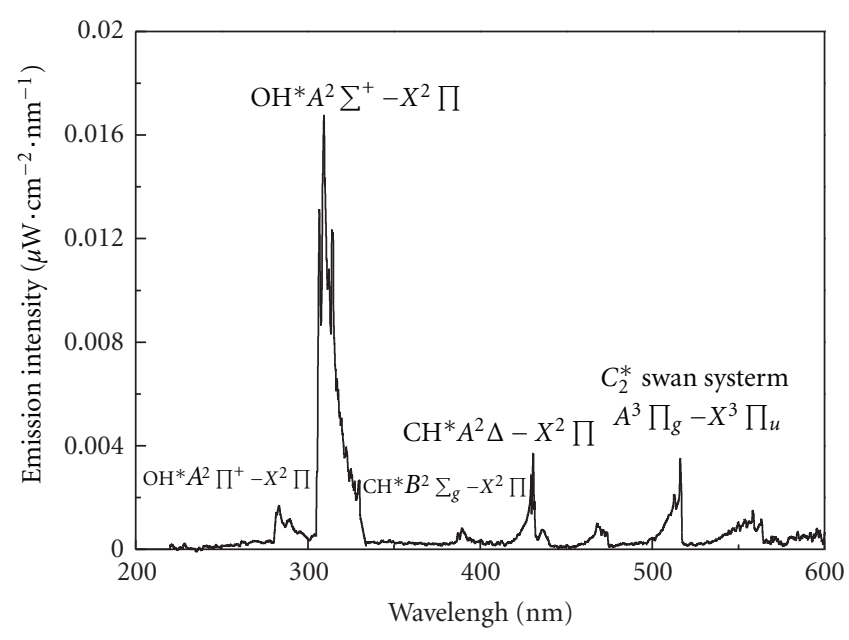

Figure 3: Typical spectrum of $\mathrm{CH}_{4} / \mathrm{O}_{2}$ diffusion flame ( $3 \mathrm{~mm}$ above the nozzle exit).

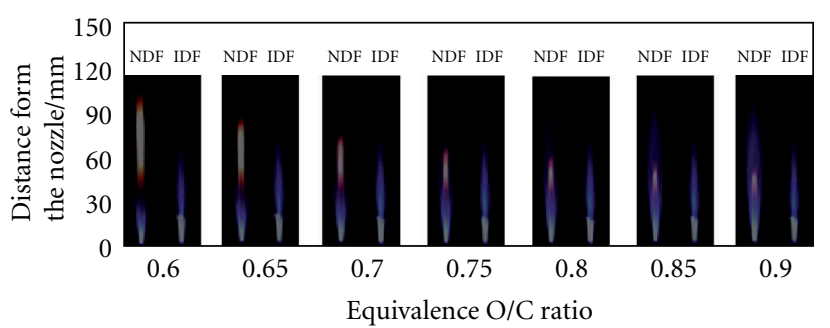

FIgURE 4: The comparison of appearance between NDFs and IDFs.

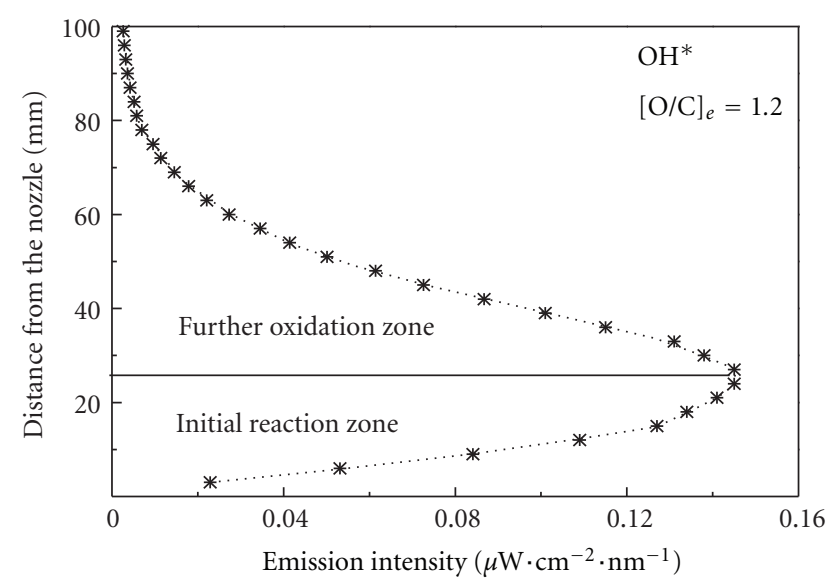

Figure 5: Two regions of the entire flame separated by $\mathrm{OH}^{*}$ maximum (condition 13). 


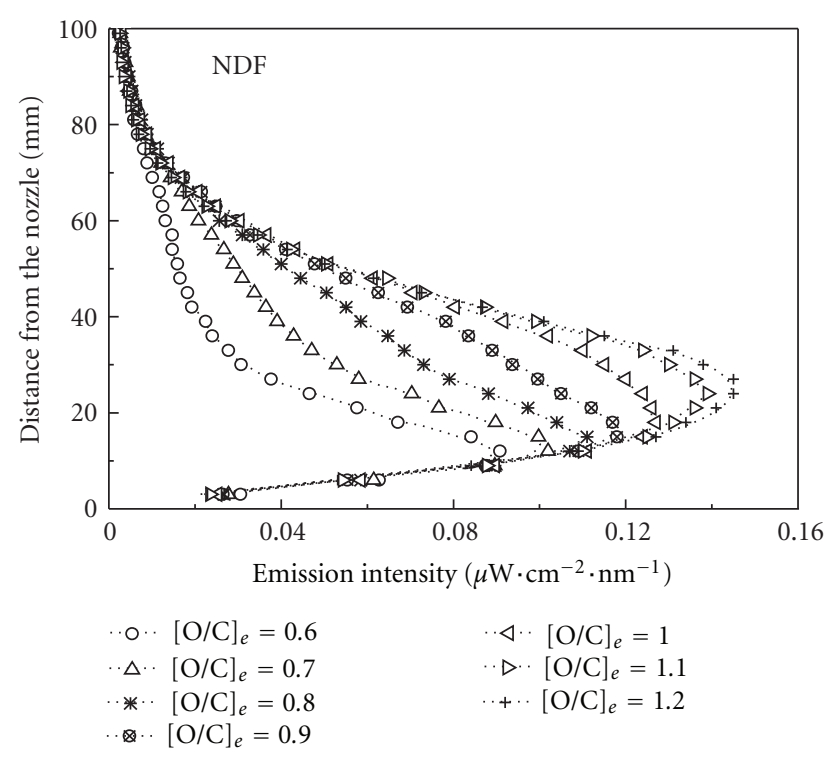

FIGURE 6: The change of $\mathrm{OH}^{*}$ distribution with increasing $[\mathrm{O} / \mathrm{C}]_{e}$ for NDFs.

With the increase of $[\mathrm{O} / \mathrm{C}]_{e}$, the change of $\mathrm{OH}^{*}$ distribution in Region II is much more significant than Region I (Figure 6). $\mathrm{OH}^{*}$ generated in Region I is basically the same, and only more fuel is consumed along the flame propagation direction, causing the originally position of the stable flamefront move downstream. At lower $[\mathrm{O} / \mathrm{C}]_{e}$, the unburned fuel and carbon particles decomposed by fuel cannot be further oxidized due to the absence of $\mathrm{O}_{2}$, which forms the obvious upper luminous zone (yellow) as shown in Figure 4. Under fuel-lean condition, the adequate supply of oxygen provides the opportunity for further oxidation, leading to the increase in $\mathrm{OH}^{*}$ generation. The degree of the further oxidization taking place in Region II is conspicuous in accordance with $\mathrm{OH}^{*}$ distribution, which is the main difference in reaction zone between fuel-rich and fuel-lean condition for NDF.

3.4. The Comparison of $\mathrm{OH}^{*}, \mathrm{CH}^{*}$ Distributions between NDFs and IDFs. Figure 7 shows the $\mathrm{OH}^{*}$ distributions for different $[\mathrm{O} / \mathrm{C}]_{e}$ of IDFs. The profiles have changed little with the increase of $[\mathrm{O} / \mathrm{C}]_{e}$. The position of maximum $\mathrm{OH}^{*}$ is still the boundary point of IDFs, and the upstream region is initial reaction region, downstream region is further oxidization region. Region I corresponds to the flame relatively bright base, which is only a quarter of the entire flame. Unlike NDFs, the change of $\mathrm{OH}^{*}$ distribution with increasing $[\mathrm{O} / \mathrm{C}]_{e}$ in Region II is not obvious, and the $\mathrm{OH}^{*}$ peak position does not move, indicating the reaction zone of IDF has no change basically for different $[\mathrm{O} / \mathrm{C}]_{e}$ (Figure 8).

At the same $[\mathrm{O} / \mathrm{C}]_{e}\left([\mathrm{O} / \mathrm{C}]_{e}=0.70\right)$, the $\mathrm{OH}^{*}$ generated in IDF is significantly more than NDF, and the distributing area is wider, as a result of more fuel and oxygen involved in the reaction. $\mathrm{CH}^{*}$ is concentrated near the nozzle exit (less than $30 \mathrm{~mm}$ above the nozzle), with relatively weaker radiation comparing with $\mathrm{OH}^{*}$. The production of $\mathrm{CH}^{*}$ in IDF is also more than NDF. The comparative velocity of the

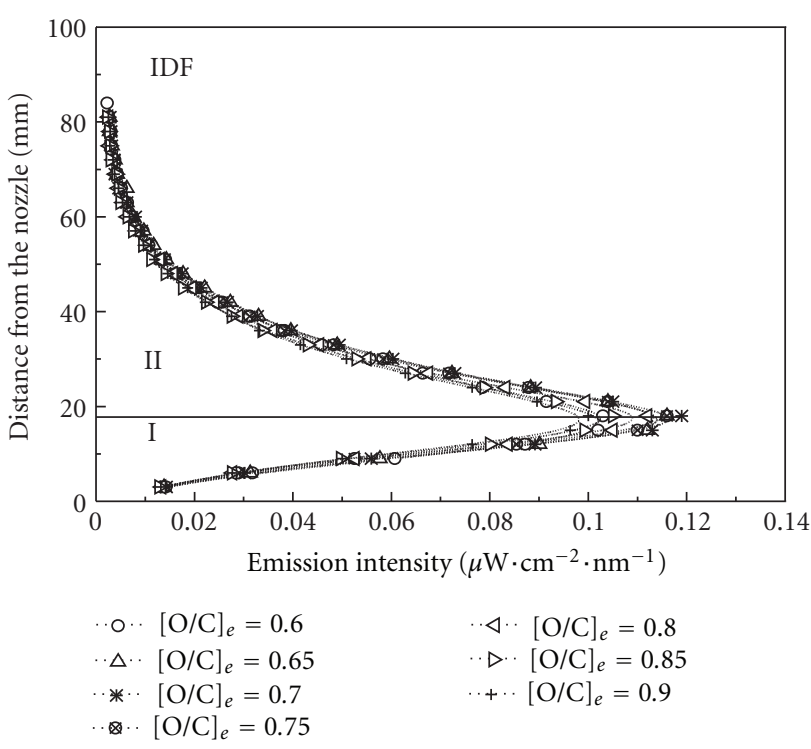

FIGURE 7: The change of $\mathrm{OH}^{*}$ distribution with increasing $[\mathrm{O} / \mathrm{C}]_{e}$ for IDFs.

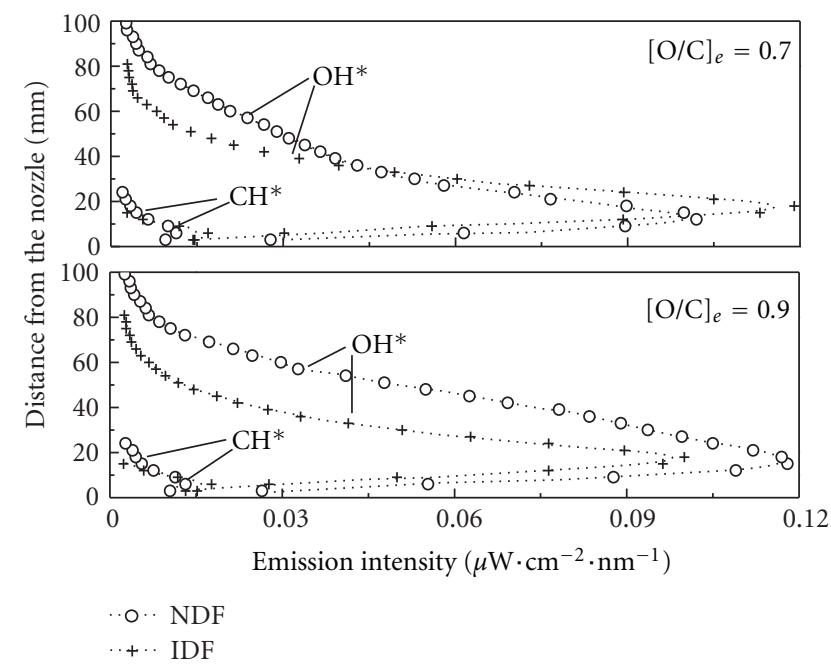

FIgURE 8: The comparison of $\mathrm{OH}^{*}, \mathrm{CH}^{*}$ distributions between NDFs and IDFs.

fuel and oxygen will be increased with higher oxygen speed, causing a stronger shearing action between these two flows, so that the inner high-speed $\mathrm{O}_{2}$ flow promotes the mixing of fuel and oxygen in IDF. Due to this promotion effect, most of the fuel is oxidized in Region I, which may be the reason that the change of $\mathrm{OH}^{*}$ distribution with increasing $[\mathrm{O} / \mathrm{C}]_{e}$ in Region II is not obvious for IDF.

Under the relatively high $[\mathrm{O} / \mathrm{C}]_{e}$ condition $\left([\mathrm{O} / \mathrm{C}]_{e}=\right.$ 0.90 ), the distributions of $\mathrm{OH}^{*}$ and $\mathrm{CH}^{*}$ in NDF become wider significantly, indicating that more fuel is oxidized, and the upper yellow zone is reduced correspondingly. But for IDF, both the $\mathrm{OH}^{*}$ and $\mathrm{CH}^{*}$ radiations decrease relatively compared with lower $[\mathrm{O} / \mathrm{C}]_{e}$, leading to the NDF exceeding IDF in the productions of $\mathrm{OH}^{*}$ and $\mathrm{CH}^{*}$. 


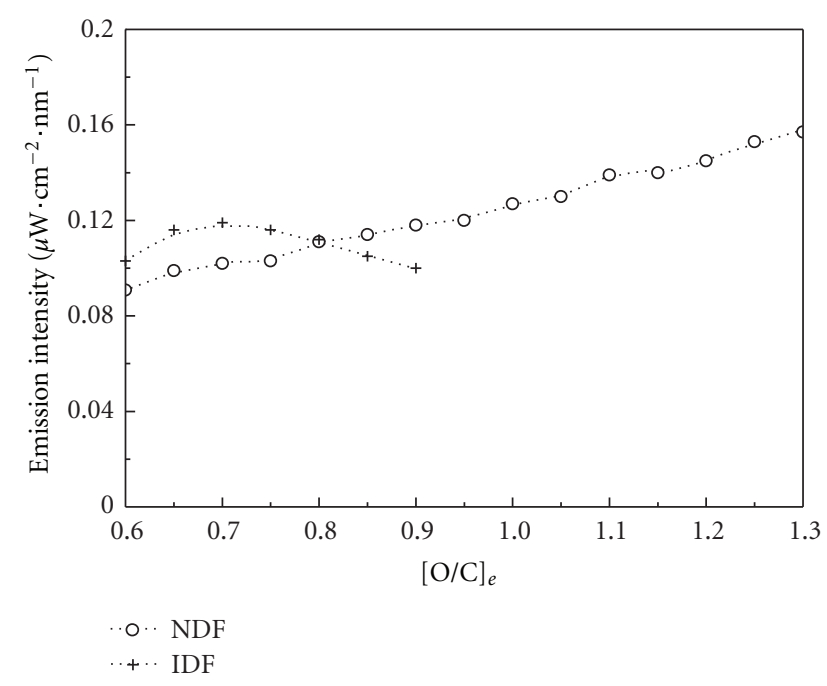

FIgURE 9: The variation of maximum $\mathrm{OH}^{*}$ emission with different $[\mathrm{O} / \mathrm{C}]_{e}$.

Figure 9 is the variation of maximum $\mathrm{OH}^{*}$ emission with different $[\mathrm{O} / \mathrm{C}]_{e}$. $\mathrm{OH}^{*}$ peak increases regularly in NDF as the $[\mathrm{O} / \mathrm{C}]_{e}$ increases, because of the enrichment of $\mathrm{O}$ and $\mathrm{O}_{2}$ and increasing temperature. The peak intensities of $\mathrm{OH}^{*}$ show a trend from ascent to descent for IDF. The inner high-speed $\mathrm{O}_{2}$ flow promotes the mixing of fuel and oxygen certainly under relatively low $[\mathrm{O} / \mathrm{C}]_{e}$. The downtrend may be caused by the variation of flame temperature. According to the research about the temperature of IDF [8], a trend from increasing to decreasing is appeared with increasing equivalence $\mathrm{O} / \mathrm{C}$ ratio, and the generation of $\mathrm{OH}^{*}$ is influenced by the temperature to a certain extent.

\section{Conclusions}

The chemiluminescence distribution characteristics of excited radicals $\left(\mathrm{OH}^{*}\right.$ and $\left.\mathrm{CH}^{*}\right)$ along the axis of NDFs and IDFs with different equivalence $\mathrm{O} / \mathrm{C}$ ratios have been measured. Furthermore, the detailed differences of reaction zones and structures between NDFs and IDFs are investigated by analyzing the chemiluminescence property combining along with the image analysis. The results can be summarized as follows.

(1) The IDF is composed of two regions: a relatively bright base and a tower on top of the base, on account of the entrainment of some fuel into the central oxygen flow under relatively higher inlet oxygen velocity condition.

(2) The entire flame has two regions along the axis separated by the maximum $\mathrm{OH}^{*}$ emission. Region I is initial reaction zone, where fuel and oxygen are mixed partially depending on the action of interdiffusion. Region II is further oxidation zone, because the combustion products of Region I, residual oxygen and a small quantity of fuel are further oxidized in this region. According to $\mathrm{OH}^{*}$ distribution, the main difference of reaction zone between fuel-rich condition and fuel-lean condition for NDF, is that whether the further oxidization takes place in the Region II.

(3) The change of $\mathrm{OH}^{*}$ distribution with increasing $[\mathrm{O} / \mathrm{C}]_{e}$ in Region II is not obvious for IDF. At lower $[\mathrm{O} / \mathrm{C}]_{e}$, the $\mathrm{OH}^{*}$ generated in IDF is significantly more than that in NDF, and the distributing area is wider, because of the inner high-speed $\mathrm{O}_{2}$ flow promoting the mixing of fuel and oxygen. Under the relatively high $[\mathrm{O} / \mathrm{C}]_{e}$ condition, the NDF exceeds IDF in the productions of $\mathrm{OH}^{*}$ and $\mathrm{CH}^{*}$, which may be caused by the variation of IDF temperature.

\section{Acknowledgments}

This work is financially supported by the National Nature Science Foundation of China (21176078) and the National Key State Basic Research Development Program of China (973 Program, 2010CB227004).

\section{References}

[1] S. Mahesh and D. P. Mishra, "Flame structure of LPG-air inverse diffusion flame in a backstep burner," Fuel, vol. 89, no. 8, pp. 2145-2148, 2010.

[2] C. R. Shaddix, T. C. Williams, L. G. Blevins, and R. W. Schefer, "Flame structure of steady and pulsed sooting inverse jet diffusion flames," Proceedings of the Combustion Institute, vol. 30, no. 1, pp. 1501-1508, 2005.

[3] H. Cheng, Z. H. Dai, Y. Q. Wang, Q. H. Guo, Q. F. Liang, and F. C. Wang, "Properties of co-axial jet free diffusion flame of coke oven gas," Journal of Combustion Science and Technology, vol. 16 , pp. $560-564,2010$.

[4] K. T. Wu, The Ohio State University, 1984.

[5] T. Takagi, Z. Xu, and M. Komiyama, "Preferential diffusion effects on the temperature in usual and inverse diffusion flames," Combustion and Flame, vol. 106, no. 3, pp. 252-260, 1996.

[6] C. R. Kaplan and K. Kailasanath, "Flow-field effects on soot formation in normal and inverse methane-air diffusion flames," Combustion and Flame, vol. 124, no. 1-2, pp. 275-294, 2001.

[7] M. A. Mikofski, T. C. Williams, C. R. Shaddix, and L. G. Blevins, "Flame height measurement of laminar inverse diffusion flames," Combustion and Flame, vol. 146, no. 1-2, pp. 63-72, 2006.

[8] L. K. Sze, C. S. Cheung, and C. W. Leung, "Appearance, temperature, and NOx emission of two inverse diffusion flames with different port design," Combustion and Flame, vol. 144, no. 1-2, pp. 237-248, 2006.

[9] B. Higgins, M. Q. McQuay, F. Lacas, and S. Candel, "An experimental study on the effect of pressure and strain rate on $\mathrm{CH}$ chemiluminescence of premixed fuel-lean methane/air flames," Fuel, vol. 80, no. 11, pp. 1583-1591, 2001.

[10] A. Sanz, J. Ballester, R. Hernández, and L. M. Cerecedo, "Advanced monitoring of industrial burners based on fluctuating flame signals," Fuel, vol. 87, no. 7, pp. 1063-1075, 2008.

[11] T. Boushaki, S. Guessasma, and J. C. Sautet, "Predictive analysis of combined burner parameter effects on oxy-fuel flames," 
Applied Thermal Engineering, vol. 31, no. 2-3, pp. 202-212, 2011.

[12] S. Keyvana, R. Rossowa, C. Romerob, and X. C. Li, "Comparison between visible and near-IR flame spectra from natural gasfired furnace for blackbody temperature measurements," Fuel, vol. 83, no. 9, pp. 1175-1183, 2004.

[13] T. Kathrotia, M. Fikri, M. Bozkurt, M. Hartmann, U. Riedel, and C. Schulz, "Study of the $\mathrm{H}+\mathrm{O}+\mathrm{M}$ reaction forming $\mathrm{OH} *$ : Kinetics of $\mathrm{OH} *$ chemiluminescence in hydrogen combustion systems," Combustion and Flame, vol. 157, no. 7, pp. 1261-1273, 2010.

[14] A. J. Marchese, F. L. Dryer, V. Nayagam, and R. O. Colantonio, "Hydroxyl radical chemiluminescence imaging and the structure of microgravity droplet flames," Symposium (International) on Combustion, vol. 26, no. 1, pp. 1219-1226, 1996. 

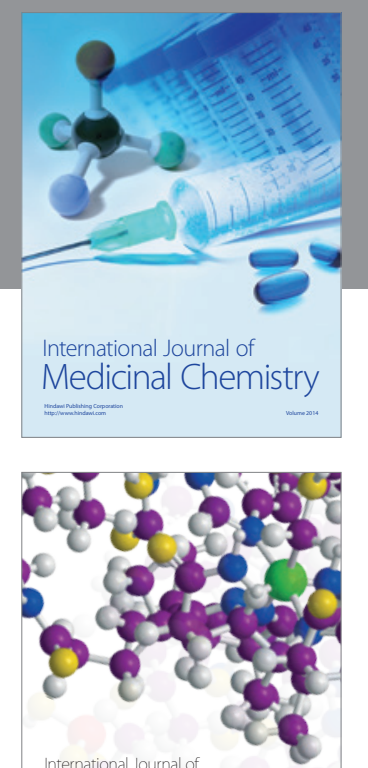

\section{Carbohydrate} Chemistry

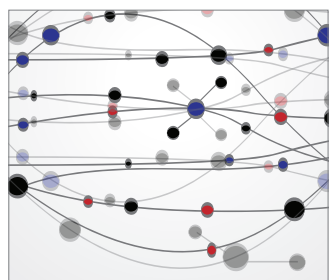

The Scientific World Journal
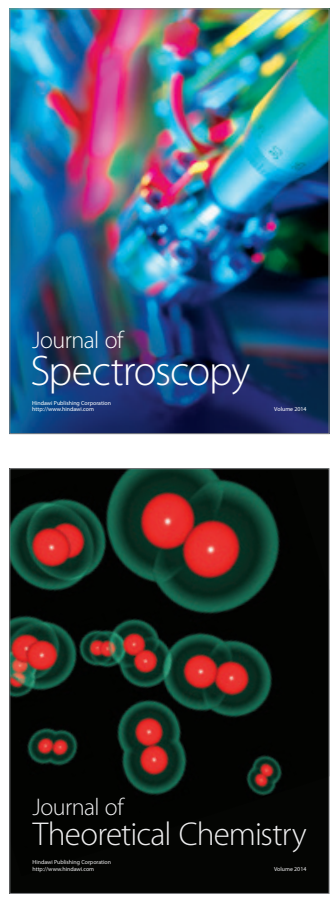
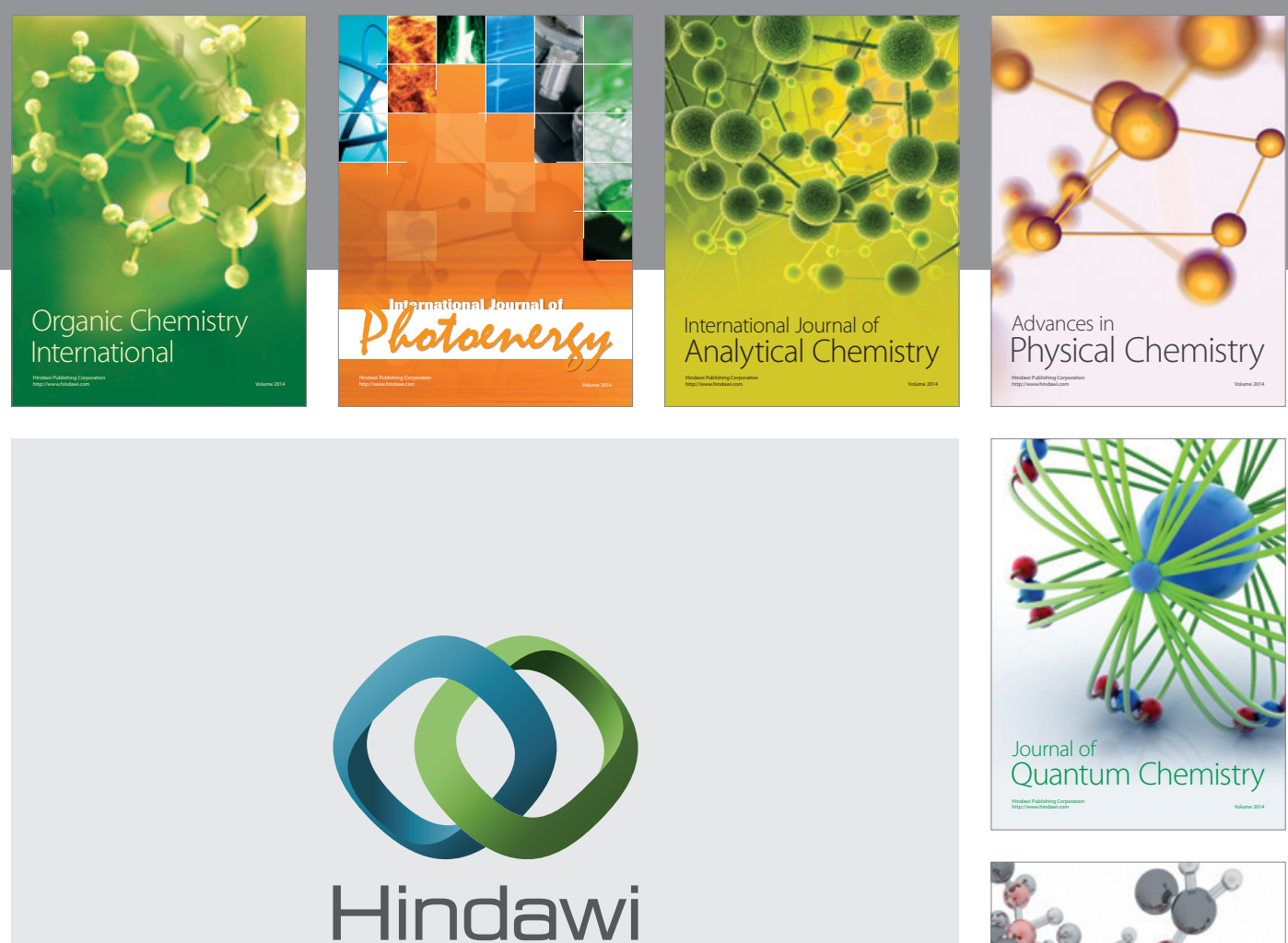

Submit your manuscripts at

http://www.hindawi.com

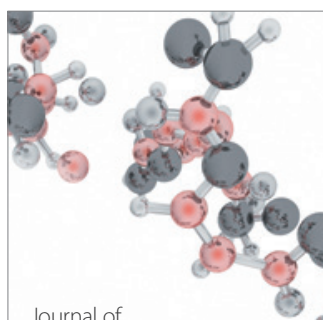

Analytical Methods

in Chemistry

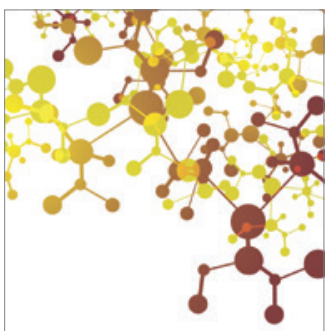

Journal of

Applied Chemistry

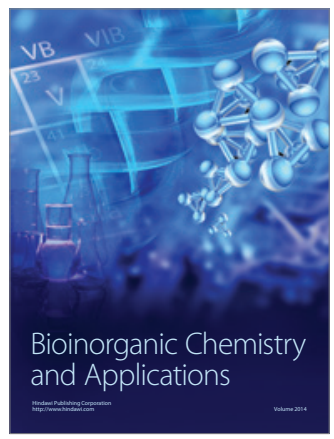

Inorganic Chemistry
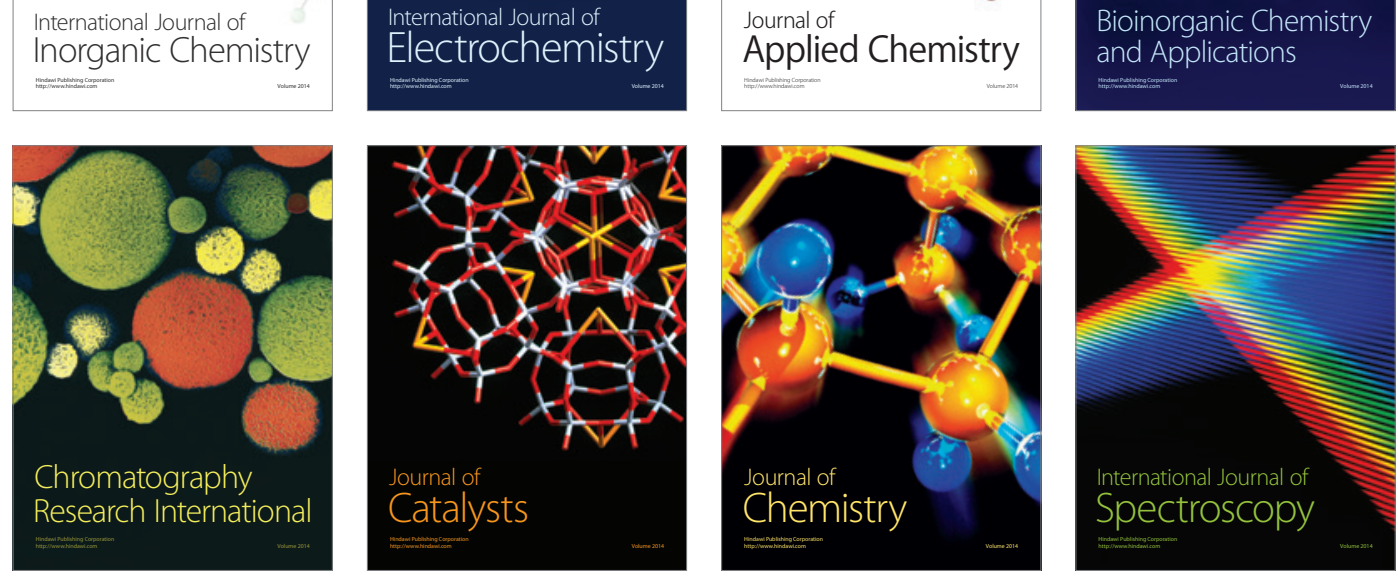